\title{
The Impact of Social and Interpersonal Resources on Adjustment Disorder Symptoms in Older Age
}

Fankhauser, S ; Pepe, A ; Wagner, B ; Krammer, S ; Aeschbach, M ; Maercker, Andreas ; Forstmeier, Simon

\begin{abstract}
This study investigates self-efficacy and motivation regulation as possible mediators of the relationship between social and interpersonal resources (i.e., social network, social support, social acknowledgment as a victim, and disclosure) and adjustment disorder (AJD) symptoms in a sample of 121 adults aged 65-97 years. AJD was conceptualized as a form of stress-response syndrome, core symptoms of which are intrusions, avoidance, and failure to adapt after having experienced a critical event. Motivational variables mediated the relationship between social acknowledgment and AJD symptoms. Contrary to expectations, motivational variables were not found to mediate the link between reluctance to disclose and AJD symptoms. This study casts new light on the psychological processes that enable older adults to adjust to critical life events and to exhibit resilience, which is important for successful aging.
\end{abstract}

DOI: https://doi.org/10.1024/1662-9647/a000022

Posted at the Zurich Open Repository and Archive, University of Zurich

ZORA URL: https://doi.org/10.5167/uzh-54854

Journal Article

Accepted Version

Originally published at:

Fankhauser, S; Pepe, A; Wagner, B; Krammer, S; Aeschbach, M; Maercker, Andreas; Forstmeier, Simon (2010). The Impact of Social and Interpersonal Resources on Adjustment Disorder Symptoms in Older Age. GeroPsych, 23(4):227-241.

DOI: https://doi.org/10.1024/1662-9647/a000022 
Running head: ADJUSTMENT DISORDER SYMPTOMS IN OLDER AGE

The Impact of Social and Interpersonal Resources on Adjustment Disorder Symptoms in Older Age: Motivational Variables as Mediators?

Sonja Fankhauser, Birgit Wagner, Sandy Krammer, Mirjam Aeschbach, Alessandra Pepe, Andreas Maercker, \& Simon Forstmeier

University of Zurich

Zurich, Switzerland

Correspondence concerning this article should be addressed to Sonja Fankhauser, Department of Psychology, Division of Psychopathology and Clinical Intervention, University of Zurich, Binzmuehlestr. 14/17, 8050 Zurich, Switzerland. E-mail: s.fankhauser@psychologie.uzh.ch 
Abstract. This study investigates general self-efficacy and motivation regulation as possible mediators of the relationship between social and interpersonal resources (social network, social support, social acknowledgment as a victim, and disclosure) and adjustment disorder (AJD) symptoms in a sample of 121 adults aged between 65 and 97 years. AJD was conceptualized as a form of stress-response syndrome, core symptoms of which are intrusions, avoidance of reminders, and failure to adapt after having experienced a critical event. Motivational variables mediated the relationship between social acknowledgment and adjustment disorder. Contrary to expectations, reluctance to disclose stressful experiences mediated the relationship between general self-efficacy and adjustment disorder. The link between motivation regulation and AJD symptoms was neither mediated by disclosure nor social acknowledgment, suggesting that motivation regulation has a considerably stronger direct effect on AJD symptoms than does self-efficacy. This study casts new light on the psychological processes that enable older adults to adjust to critical life events and to exhibit resilience, which is important for successful aging.

Keywords: adjustment disorder, self-efficacy, motivation regulation, social support, social acknowledgment, disclosure

Word count (abstract, text, references): 8555 
The Impact of Social and Interpersonal Resources on Adjustment Disorder Symptoms in Older Age: Motivational Variables as Mediators?

\section{Introduction}

Gerontology and geriatrics have traditionally focused on the diseases and disabilities that are often associated with aging. In recent decades, however, research attention has shifted to resilience factors and to resources that can help people cope with the challenges of aging and with critical life events in old age. More than 20 years ago, McCrae and Costa (1988) explored resilience factors in widowed men and women and concluded that social and personal resources help people to adapt to stressful life events such as the loss of a significant other. Since then, much research has shown that social variables such as social network and social support (e.g., Antonucci, Fuhrer, \& Dartigues, 1997; Russell \& Cutrona, 1991) and personal resources such as optimism and self-efficacy (Bandura, 1997) influence how older people cope with stressors and remain healthy. Furthermore, these two classes of resources seem to interact in their influence on wellbeing. In particular, self-efficacy and related motivational constructs have been found to mediate the relationship between social support and wellbeing (Antonucci, 2001).

The potential mechanisms by which social resources influence mental health are less clear (Berkman, Glass, Brissette, \& Seeman, 2000). In this study, we focus on adjustment disorder (AJD), one of the most frequent psychiatric diagnoses, which is sometimes developed after a critical life experience (Strain et al., 1998). As Uchino (2009) has pointed out, distinct measures of social resources variables may have differential relationships to health variables. Two interpersonal resources seem to be particularly important for coping with critical life events: the depth of disclosure about the event (Müller, Moergeli, \& Maercker, 2008) and social acknowledgment as a victim of the event (Maercker \& Müller, 2004). Additionally, we would like to suggest that distinct mediators may have differential effects on these relationships. This study therefore examines self-efficacy and motivation 
regulation, two important motivational variables, as possible mediators of the association between social/interpersonal resources and AJD symptoms. We consider not only the traditionally assessed social resources (i.e., social support and social network), but also the stressor-related interpersonal variables of disclosure and social acknowledgment as a victim.

\section{Adjustment Disorder}

The fourth edition of the Diagnostic and Statistical Manual of Mental Disorders (DSM-IV-TR) defines AJD as a transient maladaptive reaction to identifiable psychosocial stressors or changes in life circumstances (American Psychiatric Association, 2000).

However, researchers have noted that this definition is rather loose, that its validity is unsatisfactory, and that the concept in general has suffered academic neglect (Casey, Dowick, \& Wilkinson, 2001). At the same time, AJD is frequently used as a residual category for patients who do not meet the full diagnostic criteria for other disorders, such as major depressive disorder or anxiety disorders. AJD is particularly relevant in old age, when there is an accumulation of events requiring adjustment (e.g., physical, cognitive, and social losses; (Hardy, Concato, \& Gill, 2002).

Maercker, Einsle, and Köllner (2007) have proposed a new diagnostic model of AJD that addresses some of these criticisms. This model is based on the idea that AJD is a stressresponse syndrome, like posttraumatic stress disorder (PTSD), acute stress disorder, or complicated grief (Horowitz, 1997). However, AJD is characterized by the presence of a psychosocial stressor of a different quality or magnitude than PTSD (non-life-threatening; e.g., divorce, severe illness, caring for a sick family member, severe conflict in the family, or relocation), as well as by three core symptom categories: intrusion (e.g., recurrent recollections of the event), avoidance (e.g., of stimuli associated with the event), and failure to adapt (e.g., loss of interest in leisure activities, trouble sleeping). The full list of proposed diagnostic criteria for AJD is provided elsewhere (Maercker et al., 2007). Furthermore, subtypes of AJD can be specified in congruence with the DSM-IV diagnosis: depressed 
mood, anxiety, mixed emotional features, disorders of impulse control, and mixed or unspecified subtypes. According to DSM-IV, AJD can only be diagnosed in the absence of other mental disorders such as major depressive disorder. According to the new model, in contrast, AJD can be diagnosed even if other axis I disorders are present. The major advantage of the new model is that it defines the psychopathological mechanisms underlying AJD, namely interaction among the symptoms of intrusion, avoidance, and maladaptation.

The new AJD model and diagnostic procedure has already been applied in several studies: in a sample of patients with implanted cardiac defibrillators (Maercker et al., 2007), in a community sample of older adults (Maercker et al., 2008), and in a sample of refugees (Dobricki, Komproe, de Jong, \& Maercker, 2009). In the representative sample of older adults, $52 \%$ had experienced an index stressor and $4.4 \%$ fulfilled the criteria for AJD after experiencing a stressor (Maercker et al., 2008).

\section{Social and Interpersonal Resources and Adjustment to Stressors}

It is generally agreed that social relationships and social networks have a powerful impact on health (K. P. Smith \& Christakis, 2008) and mortality (Dalgard \& Lund Haheim, 1998) across the lifespan. Patients with AJD have been found to report significantly less social support than normal controls (Furukawa, Harai, Hirai, Kitamura, \& Takahashi, 1999). Despite the enormous amount of research concerning different aspects of social relations, social support, and related concepts, there is no consensus on the conceptualization used in this area of research. There is a multitude of concepts regarding social resources which are not synonymous. The conceptual framework by Due, Holstein, Lund, Modvig, and Avlund (1999) suggests a division of social relations into structural and functional social characteristics. The structural aspect of social relations includes the size of the social network whereas the functional aspects include the quality of social relationships and social support. While the structure of social relationships contains besides the number of social relations also the frequency of contact with others, the diversity of social relations and the reciprocity of social 
relations, the function of the social network can also be defined as the interpersonal interactions within the structure of the social relations covering social support, social anchorage and relational strain (Avlund, Lund, Holstein et al. 2004).

Taking into account research on interpersonal resources in the context of critical life events and AJD, two aspects are frequently neglected, namely depth of disclosure about the event in the social network (Müller, Moergeli, \& Maercker, 2008) and social acknowledgment as a victim of the event (Maercker \& Müller, 2004). Disclosure means the oral or written communication of stressful life events and of the associated thoughts and emotions (Pennebaker, 1993). Experimental research on disclosure with nonclinical samples indicates that talking about upsetting experiences is associated with better wellbeing (Esterling, L'Abate, Murray, \& Pennebaker, 1999). The results of research on disclosure in grief and PTSD are mixed: Studies have found positive (Seagal, Bogaards, Becker, \& Chatman, 1999), no (Stroebe, Stroebe, Schut, Zech, \& van den Bout, 2002), and negative associations (Gidron, Peri, Connolly, \& Shalev, 1996). The effect may be dependent on the time of disclosure after the event and on the reaction of the person to whom the experience was disclosed. It also seems important to differentiate several aspects of disclosure. In this study, we distinguish reluctance to disclose, urge to disclose, and emotional reaction during disclosure (Müller, Moergeli, \& Maercker, 2008).

The beneficial impact of disclosure depends, among other factors, on the reaction of the person confided in (Lepore, Silver, Wortman, \& Waymont, 1996). If the victim experiences social disapproval and criticism, the event may not be fully cognitively processed, with detrimental effects on recovery. For example, psychological adjustment to breast cancer has been shown to be influenced positively by the extent to which the victim's experiences are consensually validated by her social network (Cordova, Cunningham, Carlson, \& Andrykowski, 2001). Maercker and Müller (2004) define social acknowledgment "as a 
victim's experience of positive reactions from society that show appreciation for the victim's unique state and acknowledge the victim's current difficult situation" (p. 345).

\section{Motivational Variables and Adjustment to Stressors}

Bandura's (1997) social cognitive theory, with its core construct of self-efficacy, has inspired a different line of research. Self-efficacy can be defined as the belief in being able to bring an intended behavior to a successful conclusion through one's own actions. There is much empirical evidence for its links to mental health: Self-efficacy beliefs help individuals to adapt to stressors (Bandura, 1998), show strong positive associations with wellbeing (Bandura, 1997) and predict better coping with and recovery from somatic diseases. Furthermore, self-efficacy beliefs correlate negatively with depression and anxiety (Luszczynska, Gutiérrez-Doña, \& Schwarzer, 2005). Even in very old age, self-efficacy contributes to self-regulatory adaptation to stress (Jopp \& Rott, 2006) and is associated with more positive perceptions of difficult situations. Therefore, a high level of self-efficacy might result in interpreting risky situations as a challenge rather than threat (Krueger and Dickson, 1993) which in turn leads to a lower stress level and better coping with stress-inducing events.

As recovery from stress can be analyzed as a process of self-regulation, the selfregulatory skill of motivation regulation is an important factors when coping with stressful situations (Beckmann \& Kellmann, 2004). Motivation regulation can be defined as the skill of motivating oneself to persevere (Kuhl, 2000). This skill helps the individual to cope with critical life events by the process of refocusing on new, attainable goals and motivating oneself to reach these goals. In addition, is negatively associated with various mental disorders including AJD (Forstmeier \& Rüddel, 2007; Kuhl \& Fuhrmann, 1998). Since selfefficacy is strongly associated with motivational processes, both motivation regulation and self-efficacy are referred to by the umbrella term "motivational variables" in this text. However, the distinction between the two constructs has to be kept in mind. While motivation regulation is a skill or ability, self-efficacy is conceptualized as a belief. The nature of 
association between self-efficacy and motivation regulation is not tested in the present study; however, in the model proposed and tested by Beckmann \& Kellmann (2004), self-efficacy is a more distant determinant of the adaptation to stressors and motivation regulation a more proximal determinant.

\section{Mediation Effects}

The social and motivational research approaches to wellbeing and adaptation to stressors have been brought together by investigations of whether the two sets of variables are connected by mediation effects (see Baron \& Kenny, 1986). Theoretically, moderator effects could also explain the association between social and motivational variables and AJD symptoms. Yet, previous studies on the relationship between social resources and well-being suggest mediation effects. The mediation effect might operate in either of two ways: Motivational variables might mediate the relationship between social support and wellbeing, or social support might mediate the relationship between motivational variables and wellbeing. In fact, most research has supported the first effect and is thus in line with the support/efficacy model in old age proposed by Antonucci and Jackson (1987). According to their model, supportive others can help people to adapt to the challenges of aging by helping older people achieve their goals. Especially in old age, maintaining competence is best achieved through supportive interactions with others. Even the belief of the support provider in the efficacy or ability of the supported person may eventually influence his or her selfefficacy beliefs. In turn, fluctuation of support availability may threaten self-efficacy beliefs.

There is empirical evidence that self-efficacy is one of the psychosocial pathways through which social support operates (Berkman, Glass, Brissette, \& Seeman, 2000). For example, Bisconti and Bergeman (1999) showed that perceived control, a construct similar to self-efficacy, mediates the relationship between social support and wellbeing in old age. Smith et al. (2000) found that the effect of emotional support on wellbeing in old age was mediated by interpersonal agency (i.e., achieving goals through interaction with others) and 
perceived primary control (similar to general self-efficacy beliefs). Fiori, Mcllvane, Brown, and Antonucci (2006) identified social self-efficacy as a partial mediator between social relations and depression in old age.

In the context of stress-response syndromes, Benight \& Bandura (2004) suggested that self-efficacy mediates the effect of social support on posttraumatic recovery, highlighting the importance of victims' belief in their ability to cope with adverse life events. This effect has been investigated in several samples of PTSD patients—-for example, after war traumas (Solomon, Benbenishty, \& Mikulincer, 1991) and natural disasters (Benight \& Harper, 2002). However, to our knowledge, no previous study has investigated this mediation effect in AJD patients.

The association between self-efficacy and social support seems to be reciprocal. While social support enhances self-efficacy, it may also be the case that self-efficacy elicits higher levels of social support. Results from a study by Holohan and Holohan (1987) showed that self-efficacy predicted depression in old age one year after baseline, and that this association was mediated partly by social support. Antonucci and Jackson (1987) describe in their model the positive influence of certain aspects of social support on self-efficacy beliefs. Because self-efficacy beliefs are reinforced through the positive attitude of the supportive person towards the abilities of the supported person, his or her ability to face new situations may actually augment, which in turn reinforces the positive perceptions of the supportive person concerning the other person's self-efficacy. These positive perceptions or believing in someone can be interpreted as social or, more precisely, emotional support towards the person that is believed in. This emotional support can be provided, e.g., by encouraging the person concerned in a difficult situation and reminding him or her of his successful coping with similar critical events in the past.

Theoretically, different measures of social support and motivational variables may interact differently in influencing wellbeing and adjustment to stressors. To our knowledge, 
no study has investigated the influence of other social and interpersonal resources such as social network, disclosure, and social acknowledgment on self-efficacy and motivation regulation in the context of adaption to stressors. As interpersonal resources (disclosure and social acknowledgment) are more specifically related to the adaption to stressful and traumatic experience and directly refer to the interpersonal behavior and attitude of the involved social network towards the stressful event, they might be more relevant in this context than general social support and social network. In this study, we therefore apply several measures of social resources and motivational variables.

\section{The Present Study}

The goal of this study was to explore motivational variables (motivation regulation and general self-efficacy) as possible mediators of the relationship between social /interpersonal resources (social network, social support, social acknowledgment as a victim, and disclosure) and AJD symptoms in old age. We hypothesized that (1) social/interpersonal resources correlate with AJD symptoms; (2) motivational variables correlate with AJD symptoms; and (3) the relationship between social/interpersonal resources and AJD symptoms is mediated by motivational variables.

\section{Method}

\section{Participants}

Participants were 121 adults aged between 65 and 97 years. (The a-priori sample size calculation determined that 118 would be required, based on a medium effect size $f^{2}=.15$, ten predictor variables in the multiple regression, $\alpha=.05$, and $1-\beta=.80$.) All participants were cognitively healthy, community-dwelling individuals recruited in 2008 from the greater Zurich area, Switzerland, via the University for Seniors (a weekly event for individuals aged 65 and older), old people's homes, clubs for seniors (e.g., choir, exercise groups), and an advertisement in a magazine for seniors. Subjects participated voluntarily after receiving oral 
and written information about the study. Inclusion criteria were an age of at least 65 years, having experienced a critical event during the last two years, and knowledge of German. Exclusion criteria were indication of mild cognitive impairment or dementia, as determined through cognitive screening with the DemTect (Kalbe et al., 2004).

Characteristics of the sample are given in Table 1. The 121 participants (70\% women) had a mean age of 75 years (age range: 65-97) and a mean education of 13.4 years'. Almost half lived alone, $34 \%$ with a partner or other persons, and $19 \%$ in old people's homes. On average, women were less educated and more likely to live alone than men.

The most frequent stressors were disease of a family member $(22.3 \%)$, own severe disease $(16.5 \%)$, conflicts in the family $(17.4 \%)$, and relocation $(5 \%$; see Table 2 for the frequencies of all index stressors). Men and women did not differ significantly in any stressor category. The prevalence of adjustment disorder was $10.7 \%$. Again, there was no sex difference. Of the sample, $40.5 \%$ fulfilled the diagnostic criteria for the intrusion symptoms category, $24.8 \%$ the criteria for avoidance symptoms category, and $19.0 \%$ the criteria concerning symptoms for failure to adapt. On average, participants reported 2.2 of the 5 possible intrusion symptoms, 2.0 of the 6 avoidance symptoms, and 1.2 of the 5 failure to adapt symptoms.

\section{Procedure}

After an initial telephone screening for having experienced a critical life event, participants were administered a comprehensive questionnaire and several cognitive tests. The questionnaire contained a measure of AJD symptoms and self-report measures of social and motivational variables as well as physical and mental wellbeing. Cognitive screening was conducted during a 45-minute session either at the University or in the participant's home. The questionnaire was sent to participants via mail at least one week before the test session. Participants completed the questionnaire on their own, but were told that assistance was available if necessary. The cognitive test battery was administered in a comfortable room by 
graduate students with training in neuropsychological assessment. The tasks were administered to all participants in the same order. Participants signed a consent form and were mailed a detailed report on their social, motivational, and health measures as well as their cognitive performance. Their travel expenses were refunded.

\section{Measures}

\section{Adjustment Disorder}

The AJD-New Module was used to assess symptoms of AJD (AJDNM; Maercker et al., 2007). There are two parts to the measure: a stressor list and a symptom list. In its original version, the stressor list comprised 16 items assigned to seven categories (severe illness, family conflicts, divorce/separation, conflicts with colleagues/at work, illness of relative, financial problems, leaving working life) and an open category. This list was expanded to include five additional items relating to age-specific stressors (e.g., relocation, change through retirement). Participants were asked to state when and for how long they had experienced each stressor in the last two years, and to state which event had been most upsetting. The instruction "Please answer the following questions with regard to your most upsetting experience" forged a link to the second part of the measure: the symptom list used to diagnose AJD. This list consists of 29 items belonging to three core symptom categories (intrusion, avoidance, and failure to adapt) and three subtype-specifying criteria (anxiety, depression, and disturbed impulses). Specifically, the list contains five intrusion symptoms (e.g., "I keep having to think about the situation"), six avoidance symptoms (e.g., "I try not to talk about the situation"), and five items to assess failure-to-adapt symptoms (e.g., "Since the event, I have been unable to sleep well"). The subtype-specifying criteria were depressed mood (six items, e.g., "Since the event, I have felt down and sad"), anxiety symptoms (three items, e.g., "Since the event, I have been fearful in certain situations"), and impulse disturbance (three items, e.g., "I have noticed that I have been more agitated since the event"). These items were rated 
on a 4 -point scale $(1=$ never, $2=$ rarely, $3=$ mostly, and $4=$ always $)$. The next question concerned the onset of the symptoms (less than one month ago, 1 to 6 months ago, 6 months to 2 years ago). A symptom was considered to be present if the corresponding item was rated "mostly" or "always."

A previous study (Bley, Einsle, Maercker, Weidner, \& Joraschky, 2008) examined the concordance of AJD diagnoses as established by the AJDNM with conventional diagnoses of AJD as established by the Structured Clinical Interview for DSM-IV (First, Spitzer, Gibbon, $\&$ Williams, 1997). Concordance was moderate, with an error rate of $27.8 \%$. This outcome was to be expected given the different operationalizations of AJD diagnoses. The internal consistencies for subscores of intrusion (Cronbach's alpha $=.83$ ), avoidance $(.81)$, and failure to adapt (.77) were satisfactory in this study.

\section{Disclosure}

The short form of the Disclosure of Trauma Questionnaire (DTQ; Müller, Beauducel, Raschka, \& Maercker, 2000) was used to assess aspects of an individual's intention to disclose stressor events. The 12 items were rated on a 6-point Likert scale from 0 (not at all) to 5 (completely). The measure comprises three subscales of four items each: "Reluctance to talk" assesses resistance to tell others about the stressor (e.g., "I find it difficult to talk to people about the incident"), whereas "urge to talk" assesses the need to disclose the stressor events (e.g., "I feel compelled to talk about my experiences again and again"). These two subscales were independent of each other (see Table 3). The third subscale, "emotional reaction during disclosure" (e.g., "Describing the event makes me feel very sad"), was moderately positively correlated with "reluctance to talk." The DTQ was originally developed to tap communication behavior regarding traumatic events; however, because the items refer to incidents rather than to trauma, the instrument can also be used to assess nontraumatic life 
events. Its psychometric properties are good, with Cronbach's $\alpha=0.72$ to 0.82 in the present sample, and test-retest reliability of $\mathrm{r}=0.76$ to 0.89 (Müller et al., 2000).

\section{Social Acknowledgment}

The Social Acknowledgment Questionnaire (SAQ; Maercker \& Müller, 2004) was used to assess participants' perception of their recognition as a victim and of support from family, friends, acquaintances, and local authorities. The 16 items of this self-report measure were rated on a 4-point Likert scale, from 0 (not at all) to 3 (completely). It contains the three subscales: "recognition as a survivor" by significant others (e.g., "My friends feel sympathy for what happened to me"), "general disapproval" as a survivor (e.g., "Most people cannot understand what I went through"), and "family disapproval" as a survivor (e.g., "My family finds my reaction to the incident to be exaggerated"). A total score can also be calculated. A validation study revealed moderate negative intercorrelations between the first and second scale and between the first and third scale, and moderate positive intercorrelations between the second and third scale (Maercker \& Müller, 2004). Test-retest reliability over two months was good, at $r=.74$ to .85 . Cronbach's $\alpha$ for the total score and the three subscores in the present sample was $.86, .79, .82$, and .78 , respectively.

\section{Social Networks and Social Support}

Two measures were used to assess social networks and social support. Frequency of social contacts was assessed by presenting participants with a list of members of the social network (partner, children, parents, siblings, friends, neighbors, and fellow residents of old people's homes). Participants were asked to rate their frequency of contact with each individual (further key individuals could be added) on a 6-point scale (daily, once a week, once a month, several times a year, once a year, never). Their answers were recoded to generate a scale in which 1 point corresponded to one contact per week (e.g., daily $=7$ to 
never $=0$ ). The units of the scale are thus contact days per week. The composite score is the sum of contact days for each member of the network.

Perceived social support was measured by a short version of the widely used German Social Support Questionnaire (Fragebogen zur sozialen Unterstützung, FSozU; Fydrich, Sommer, Menzel, \& Höll, 1987). This 14-item questionnaire measures a composite of the individual's perceived emotional (e.g., "I have friends or family members who listen to me when I want to talk about a problem") and practical support (e.g., "I can borrow anything I need from friends or neighbors") and perception of social integration (e.g., "There is a group of people to whom I belong to and with whom I meet regularly"). This measure has been validated previously (Fydrich, Geyer, Hessel, Sommer, \& Brähler, 1999) and showed high internal consistency in the present sample, with a Cronbach's $\alpha=.92$.

\section{Motivation Regulation}

Motivation regulation was assessed with a five-item subscale of the Volitional Components Questionnaire (VCQ, Kuhl \& Fuhrmann, 1998), which measures positive selfmotivation (e.g., "I can usually motivate myself quite well if my determination to persevere weakens"). Participants rated their agreement with each statement on a 4-point scale. The internal consistency of this subscale was $\alpha=0.85$.

\section{General Self-Efficacy}

The General Self-Efficacy scale (GSE, Scholz, Gutierrez Dona, Sud, \& Schwarzer, 2002) was used to assess the "broad and stable sense of personal competence to deal effectively with a variety of stressful situations" (Scholz et al., 2002, p. 243), based on Bandura's (1977) concept of self-efficacy. Participants rated 10 items (e.g., "I am confident that I could deal efficiently with unexpected events") on a 4-point scale. The internal consistency of this subscale was $\alpha=0.89$. 


\section{Cognitive, Physical, and Mental Health}

Three scales were used to assess cognitive, physical, and mental health. Cognitive status was assessed by the DemTect (Kalbe et al., 2004), a well-validated test used to screen for mild cognitive impairment. It consists of five subtests (a word list, a number transcoding task, a word fluency task, digit span reverse, and delayed recall of the word list) and is highly sensitive for detecting and grading mild cognitive impairment. Individuals with a score under 10, indicating mild cognitive impairment or dementia, were excluded from the analyses.

The 12-item Short Form Health Survey (SF-12; Ware, Kosinski, \& Keller, 1996) was used to assess overall physical and mental health. Two summary measures, Physical (PCS) and Mental Component Summaries (MCS), were calculated based on standardized scores. Higher scores indicate better health.

\section{Statistical Analyses}

The statistical analyses were conducted with the Statistical Package for the Social Sciences (SPSS) version 17.0. Bivariate correlations were first calculated to explore the relationships among all variables. A hierarchical multiple regression analysis was then performed to identify the predictors of AJD. Given the low number of individuals with a diagnosis of AJD, the number of main symptoms (intrusion, avoidance, failure to adapt) rather than a diagnosis of AJD was used as the dependent variable of the regression. Sociodemographic variables (age group, gender, education, and health status) were entered in step 1, social and interpersonal resources in step 2, and motivational variables in step 3. Only those social/interpersonal and motivational variables that had a significant bivariate correlation with AJD symptoms were included in the regression analysis. Moreover, because the disclosure subscale "emotional reaction during disclosure" correlated very highly with AJD (see Table 3) due to the item overlap of the scales, only the "reluctance to talk" subscale 
of that measure was used. To restrict the number of predictors, we used the total score on the Social Acknowledgment Questionnaire.

A series of hierarchical regression analyses were performed to test for mediation effects. Age, gender, education, marital status, and health were controlled for in all analyses, either because of their established relationships with wellbeing or because they showed significant correlations with AJD symptoms (see Table 3). The tests of mediation effects were based on Baron and Kenny's (1986) definition of a mediator, according to which complete mediation occurs only when the effect of the independent variable is reduced to zero when controlling for the mediator. The Sobel test was used to establish the degree of mediation (Sobel, 1982). Finally, we calculated the percentage of the total effect that was mediated using the formula proposed by Mackinnon and Dwyer (1993).

\section{Results}

\section{Correlations Between Study Variables}

The correlations between sociodemographic, health, social, and motivational variables and AJD are reported in Table 3. Age group—-but not gender, years of education, or marital status - correlated with the number of main symptoms of AJD. Older individuals showed fewer symptoms of $\operatorname{AJD}(r=-.20, p<.05)$. Both motivation regulation $(r=-.32, p<.01)$ and general self-efficacy $(r=-.22, p<.05)$ correlated significantly with the number of AJD symptoms. To be able to demonstrate mediation (Baron \& Kenny, 1986), the respective predictor variable (social/interpersonal variable) has to be associated with the outcome variable (symptoms of AJD). Therefore, in a first step we focus on the correlations between these two groups of variables. Contrary to expectations, social resources did not correlate significantly with the number of AJD symptoms (social support: $r=-0.02, p>.01$; frequency of contact: $r=0.04, p>.01$ ). Two out of three disclosure scales (reluctance to talk: $r=.37, p$ $<.01$; urge to talk: $r=0.12, p>.01$; emotional reaction: $r=.60, p<.01)$ and three out of four 
social acknowledgment scales (general disapproval: $r=.41, p<.01$; family disapproval: $r=$ $.21, p<.05$; recognition as a victim: $r=0.05, p>.01$; total score: $r=-.27, p<.01$ ) were significantly associated with the number of AJD symptoms. Finally, both motivation regulation $(r=-.32, p<.01)$ and general self-efficacy $(r=-.22, p<.05)$ correlated significantly with the number of AJD symptoms.

In a second step, for a mediation effect to be present, not only does the predictor have to correlate with AJD symptoms, but the correlation between the predictor and the mediator must also be significant. Reluctance to talk correlated with motivation regulation $(r=-.18, p<$ $.05)$ and general self-efficacy $(r=-.26, p<.01)$, and the social acknowledgment total score correlated with motivation regulation $(r=.28, p<.01)$ and general self-efficacy $(r=.31, p<$ $.01)$. Therefore, only combinations of these four variables were included in the mediation models. Though social support correlated with both self-efficacy $(r=.28, p<.01)$ and motivation regulation $(r=.26, p<.01)$, it was not included in the further statistical analysis, because social support did not correlate significantly with the outcome variable (AJD symptoms).

\section{Hierarchical Regression Analysis}

Given the findings that both interpersonal resources variables (reluctance to talk and social acknowledgment) and motivational variables (motivation regulation, general selfefficacy) were associated with symptoms of AJD, the question arises which of these constructs is better able to predict AJD and whether these variables explain a significant amount of the variance in AJD symptoms after controlling for relevant demographic and health variables. A hierarchical regression analysis revealed that reluctance to talk $(\beta=0.31, p$ $<.001)$ and motivation regulation $(\beta=-0.25, p<.01)$ were the two most important predictors of AJD symptoms in old age (see Table 4). These predictors explained 33\% of the variance $\left(R^{2}=0.33 ;\right.$ effect size $\left.\varepsilon^{2}=.49 ; F(9,110)=5.92 ; p<.001\right)$. The last two columns in Table 4 show how much additional variance was explained when the respective block was included in 
the final step of the analysis. Interpersonal resources explained $8 \%$ and motivational variables $7 \%$ of the variance in AJD symptoms when all other variables were controlled.

\section{Testing Mediation Models}

Two types of mediation models were tested: first, motivational variables mediating the relationship between interpersonal resources and AJD symptoms; second, interpersonal resources mediating the relationship between motivational variables and AJD symptoms (after first results suggested this mediating effect). Table 5 presents the standardized and unstandardized beta weights for the first set of hierarchical regression analyses. In a last step, for a mediation effect to be present, the beta weight of the interpersonal resource variable (e.g. social acknowledgment or disclosure) predicting the outcome variable (AJD symptoms) should no longer remain significant after controlling for the mediator (motivational variable). There were two significant mediation effects with motivational variables (motivation regulation and self-efficacy) as a mediator of the relationship between social acknowledgment and AJD (models 3 and 4). When controlling for motivation regulation and self-efficacy, the beta weight for social acknowledgment predicting AJD symptoms was no longer significant. In contrast, motivational variables did not emerge as mediator of the association of reluctance to talk with AJD. The beta weight for reluctance to talk predicting AJD symptoms remained significant despite controlling for motivation regulation and self-efficacy.

The upper part of Figure 1 depicts general self-efficacy as a mediator of the relationship between social acknowledgment and AJD (model 4). We give details of this mediation effect to illustrate the definition of mediation according to Baron and Kenny (1986). It was first established that there was a significant association of social acknowledgment with AJD symptoms $(\beta=-0.21, p<.05)$. Second, variations in social acknowledgment significantly accounted for variations in self-efficacy $(\beta=0.30, p<.001)$.

Third, the relationship between self-efficacy and symptoms of AJD was significant $(\beta=-0.24$, $p<.01)$. Finally, when the relationship between self-efficacy and AJD symptoms was 
controlled, the association of social acknowledgment with AJD symptoms was no longer significant $(\beta=-0.14, n . s$. $)$. The Sobel test statistic confirmed this mediation effect $(z=-2.25$, $p<.05)$. According to Mackinnon and Dwyer's (1993) definition, 34\% of the effect of social acknowledgment on AJD was mediated by self-efficacy. Another mediation effect involved motivation regulation as a mediator of the relationship between social acknowledgment and AJD (model 3). The Sobel test confirmed that this mediation effect was significant $(z=-2.30$, $p<.05)$, and $35 \%$ of the total effect was mediated.

Table 6 presents the results of a second set of hierarchical regression analyses testing social and interpersonal resources mediating the relationship between motivational variables and AJD symptoms. There was one significant mediation effect involving reluctance to talk as a mediator of the relationship between general self-efficacy and AJD symptoms (model 7). The lower part of Figure 1 depicts this mediation effect. The Sobel test confirmed that this effect was significant $(z=-2.43, p<.05)$, and $34 \%$ of the total effect was mediated.

\section{Discussion}

The main goal of this study was to explore motivational variables (i.e., motivation regulation and general self-efficacy), social resources (i.e., social network, social support,) and interpersonal resources (i.e., social acknowledgment as a victim and disclosure) as predictors of AJD symptoms in old age and to identify possible mediation effects. Social support and social networks did not emerge as significant predictors of AJD symptoms; however, all other interpersonal and motivational variables correlated with adjustment. A hierarchical regression analysis revealed reluctance to talk and motivation regulation to be the two main predictors of adjustment disorder symptoms. As expected, the motivational variables self-efficacy and motivation regulation mediated the relationship between social acknowledgment and AJD symptoms. Contrary to our expectations, however, reluctance to talk mediated the relationship between general self-efficacy and AJD symptoms — and not the other way around. 
Our finding that motivational variables mediated the relationship between interpersonal resources and AJD symptoms is consistent with previous research on PTSD, depression, and general wellbeing (e.g., Benight \& Bandura, 2004; Bisconti \& Bergeman, 1999; G. C. Smith et al., 2000). It is also consistent with the support-efficacy model proposed by Antonucci and Jackson (1987), but extends that model in two important ways. First, a stressor-specific form of social support—social acknowledgment as a victim—was the independent variable in our mediation model. Whereas social support is an umbrella term for different forms of emotional and practical support, social acknowledgment as a victim is defined as the victim's perception that other people or society show appreciation-as opposed to disapproval, criticism, or rejection—of his or her experience and situation (Maercker \& Müller, 2004). Self-perceived general disapproval as a victim has been found to be positively associated with PTSD symptoms in development aid workers (Jones, Müller, \& Maercker, 2006), crime victims (Müller et al., 2008), and former political prisoners (Maercker \& Müller, 2004).

Second, our findings extend the support/efficacy model inasmuch as we found not only self-efficacy, but also motivation regulation to mediate the relationship between social acknowledgment and AJD symptoms. Of course, self-efficacy and motivation regulation are strongly correlated $(r=0.51)$ which may account for this result. However, it is important to distinguish the two constructs for theoretical and practical reasons. Self-efficacy is conceptualized as a belief, that is, a cognitive structure (Bandura, 1997); motivation regulation is described as a skill that can be operationalized as strategies to motivate oneself in the face of adverse life circumstances (Kuhl, 2000). In their empirical test of a process model of recovery from stress, Beckmann and Kellmann (2004) found that self-efficacy as a disposition was a more distant determinant of recovery from stress, whereas motivation regulation and emotion regulation were more proximal determinants. From a practical point of view, different approaches might be taken to improve self-efficacy and motivation regulation. 
Patients' self-efficacy beliefs might be enhanced by helping them to appraise themselves and the world in a more positive, optimistic way (Beck, Rush, Shaw, \& Emery, 1987), whereas motivation regulation might be improved by training concrete strategies such as subdividing larger goals into subgoals, self-rewarding for reaching subgoals, visualizing the positive consequences of coping with a challenge, and reflecting on the progress made as well as on previous successes (Forstmeier \& Rüddel, 2007).

The finding that reluctance to talk mediated the relationship between general selfefficacy (but not motivation regulation) and AJD symptoms - and not the other way aroundwas contrary to our expectations. Few studies have reported comparable findings. For example, Holohan \& Holohan (1987) showed that the relationship between self-efficacy and depression one year on was partly mediated by social support. It is important to note that all mediation effects in this study were partial—approximately one third of the effect of the independent variable on AJD symptoms was mediated by a third variable. This means that two thirds of the link between self-efficacy and health can be interpreted as direct effect, and one third attributed to the fact that self-efficacious individuals tend to disclose their experience to a trusted person. The fact that the link between motivation regulation and health was not mediated by either disclosure or social acknowledgment might be interpreted as indicating that motivation regulation has a considerably stronger direct effect on AJD symptoms than does self-efficacy.

The latter interpretation is supported by the results of the hierarchical regression analysis including all relevant variables. Motivation regulation and reluctance to talk emerged as the two main predictors of AJD symptoms, while self-efficacy and social acknowledgment lost their predictive power. These findings raise the question whether disclosure mediates the positive effect of social acknowledgment on wellbeing and adjustment to stressors. In their model of posttraumatic growth, Tedeschi and Calhoun (2004) suggested that "supportive others can aid in posttraumatic growth by providing a way to craft narratives about the 
changes that have occurred, and by offering perspectives that can be integrated into schema changes" (p. 8). Talking about the critical life event can be a crucial step in developing new perspectives, setting new goals, and finding meaning in the critical life events. The positive correlation between reluctance to talk and AJD symptoms is consistent with findings from PTSD research (e.g., Müller et al., 2008).

Interestingly, perceived social (emotional and practical) support was not correlated with AJD symptoms in this study, although previous studies have found such an association for other health outcomes (e.g., Mendes de Leon et al., 1999; K. P. Smith \& Christakis, 2008). It is possible that the measure applied in this study has critical shortcomings; for example, it is unable to differentiate between emotional and practical support and perception of social integration. It may be that emotional support is the main predictor of adjustment after a stressor (Uchino, 2009), but that its effect is masked by the other items in this onedimensional questionnaire. Furthermore, the used questionnaire might be too unspecific with regard to the adaption to stressful experiences in contrast to interpersonal resources. As mentioned before, interpersonal resources such as social acknowledgment and disclosure directly refer to the interpersonal behavior and attitude of the involved social network towards the stressful event. Hence, they might be more relevant in this context than general social support and social network which may be the explanation for the differential effects. In a previous study, subjective social acknowledgment predicted PTSD better than a conventional measure of perceived social support. This finding was attributed to the higher trauma-related specificity of the SAQ (Maercker \& Müller, 2004). Furthermore, social support might only be beneficial to the extent that the supportive person believes in the abilities of the supported person to cope with the situation. For instance, someone who is in a difficult situation might get a lot of support because he or she seems not to be able to cope. In this case, the selfefficacy of the supported person might even decrease. Again, more specific measures of social resources, especially social support, seem appropriate for further research in this area. 
Several limitations of this study must be considered. First, given its cross-sectional design, the findings represent associations and not causal effects on AJD symptoms. Longitudinal studies are needed to address questions such as how social and motivational variables interact in explaining emotional wellbeing and adjustment to stressors. Second, more than half of the sample was aged between 65 and 74 years, the participants were relatively highly educated, and more than two thirds of participants were female. Generalizations to people over 80 , of lower education, and to men should be made carefully. Further research is needed to investigate AJD in a sample of the oldest old. Third, all measures relied on self-report, and we assessed critical life stressors retrospectively. The data are thus subject to recall bias (Maughan \& Rutter, 1997), which may lead to lower event prevalence. Fourth, the outcome was not AJD but number of main symptoms of AJD. Because of power issues, we had to use this continuous variable rather than the dichotomous disease variable. Although the patterns of correlations between the predictors and the two outcome variables were very similar, we can draw conclusions only about maladjustment symptoms and not about AJD itself. Fifth, our theoretical conceptualization of AJD is relatively new. Although it has been validated in several previous studies (Dobricki et al., 2009; Maercker et al., 2007; Maercker et al., 2008), it is only moderately associated with the conventional DSM-IV diagnosis of AJD. Although the present results are limited to the measure used, they indicate that the new concept can be of great value for gerontological research, particularly in clinical settings. A further study could compare whether the effects might also be found when applying the DSM-IV diagnosis of AJD.

Despite these limitations, this study represents an important step in research on adjustment problems in old age. The results are clinically relevant. Because increasing the size or structure of the social network of an individual with AJD symptoms may not be feasible in most cases, interventions designed to increase self-efficacy and to train motivation regulation skills may lead to more success. Fostering disclosure in trusting relationships may 
have an additional effect. Further research is needed to investigate social and motivational factors in the prediction of AJD from a longitudinal perspective. Samples of patients with AJD, PTSD, and complicated grief could be compared to investigate whether the mediator model is similarly relevant in all stress-response syndromes. Furthermore, social and motivational variables should be studied as predictors of therapy outcomes in intervention studies treating patients with AJD. This study casts new light on the psychological processes that enable older adults to adjust to life events and to exhibit resilience, which is important for successful aging. 


\section{References}

American Psychiatric Association. (2000). Diagnostic and statistical manual of mental disorders (4th ed., text revision). Washington, DC: APA.

Antonucci, T. C. (2001). Social relations: An examination of social networks, social support, and sense of control. In J. E. Birren (Ed.), Handbook of the psychology of aging (5th ed., pp. 427-453). San Diego, CA: Academic Press.

Antonucci, T. C., Fuhrer, R., \& Dartigues, J. (1997). Social relations and depressive symptomatology in a sample of community-dwelling French older adults. Psychology and Aging, 12, 189-195.

Antonucci, T. C., \& Jackson, J. S. (1987). Social support, interpersonal efficacy, and health: A life course perspective. In L. L. Carstensen \& B. A. Edelstein (Eds.), Handbook of clinical gerontology (pp. 291-311). Elmsford, NY: Pergamon Press.

Avlund, K., Lund, R., Holstein B. E., Due, P., Rantala, R. S., \& Heikkinen, R. L. (2004). The Impact of Structural and Functional Characteristics of Social Relations as Determinants of Functional Decline. Journal of Gerontology, 59b, 44-51.

Bandura, A. (1977). Self-efficacy: Toward a unifying theory of behavioural change. Psychological Review, 84, 191-215.

Bandura, A. (1997). Self-efficacy: The exercise of control. New York: Freeman.

Bandura, A. (1998). Personal and collective efficacy in human adaptation and change. In J. G. Adair (Ed.), Advances in psychological sciences, Vol. 1: Social, personal, and cultural aspects (pp. 51-71). Hove, UK: Psychology Press/Erlbaum.

Baron, R. M., \& Kenny, D. A. (1986). The moderator-mediator variable distinction in social psychological research: Conceptual, strategic, and statistical considerations. Journal of Personality and Social Psychology, 51, 1173-1182.

Beck, A. T., Rush, A. J., Shaw, B. F., \& Emery, G. (1987). Cognitive therapy of depression. New York: Guilford. 
Beckmann, J., \& Kellmann, M. (2004). Self-regulation and recovery: Approaching an understanding of the process of recovery from stress. Psychological Reports, 95, $1135-1153$.

Benight, C. C., \& Bandura, A. (2004). Social cognitive theory of posttraumatic recovery: The role of perceived self-efficacy. Behavior Research and Therapy, 42, 1129-1148.

Benight, C. C., \& Harper, M. L. (2002). Coping self-efficacy perceptions as a mediator between acute stress response and long-term distress following natural disasters. Journal of Traumatic Stress, 15, 177-186.

Berkman, L. F., Glass, T., Brissette, I., \& Seeman, T. E. (2000). From social integration to health: Durkheim in the new millennium. Social Science and Medicine, 51, 843-857.

Bisconti, T. L., \& Bergeman, C. S. (1999). Perceived social control as a mediator of the relationships among social support, psychological well-being, and perceived health. Gerontologist, 39, 94-103.

Bley, S., Einsle, F., Maercker, A., Weidner, K., \& Joraschky, P. (2008). Anpassungsstörungen: Die Erprobung eines neuen diagnostischen Konzepts in einem ambulanten psychosomatischen Setting [Adjustment disorders: The exploration of a new diagnostic concept in an outpatient psychosomatic setting]. Psychotherapie, Psychosomatik und medizinische Psychologie, 58, 446-453.

Casey, P., Dowick, C., \& Wilkinson, G. (2001). Adjustment disorders. Fault line in the psychiatric glossary. British Journal of Psychiatry, 179, 479-481.

Cordova, M. J., Cunningham, L. L. C., Carlson, C. R., \& Andrykowski, M. A. (2001). Social constraints, cognitive processing, and adjustment to breast cancer. Journal of Consulting and Clinical Psychology, 69, 706-711.

Dalgard, O. S., \& Lund Haheim, L. (1998). Psychosocial risk factors and mortality: A prospective study with special focus on social support, social participation, and locus of control in Norway. Journal of Epidemiology and Community Health, 52, 476-481. 
Dobricki, M., Komproe, I. H., de Jong, J. T. V. M., \& Maercker, A. (2009). Adjustment disorders after severe life-events in four postconflict settings. Social Psychiatry and Psychiatric Epidemiology, 45, 39-46.

Due, P., Holstein, B., Lund, R., Modvig, J., \& Avlund K. (1999). Social relations: network, support and relational strain. Social Science \& Medicine, 48, 661-673.

Esterling, B. A., L'Abate, L., Murray, E. J., \& Pennebaker, J. W. (1999). Empirical foundations for writing in prevention and psychotherapy: Mental and physical health outcomes. Clinical Psychology Review, 19, 79-96.

Fiori, K. L., McIlvane, J. M., Brown, E. E., \& Antonucci, T. C. (2006). Social relations and depressive symptomatology: Self-efficacy as a mediator. Aging and Mental Health, $10,227-239$.

First, M. B., Spitzer, R. L., Gibbon, M., \& Williams, J. B. (1997). Structured Clinical Interview for DSM-IV Axis I Disorders, Clinician Version. Washington, DC: American Psychiatric Publishing.

Forstmeier, S., \& Rüddel, H. (2007). Improving volitional competence is crucial for the efficacy of psychosomatic therapy: A controlled clinical trial. Psychotherapy and Psychosomatics, 76, 89-96.

Furukawa, T. A., Harai, H., Hirai, T., Kitamura, T., \& Takahashi, K. (1999). Social Support Questionnaire among psychiatric patients with various diagnoses and normal controls. Social Psychiatry and Psychiatric Epidemiology, 34, 216-222.

Fydrich, T., Geyer, M., Hessel, A., Sommer, G., \& Brähler, E. (1999). Fragebogen zur Sozialen Unterstützung (F-SozU): Normierung an einer repräsentativen Stichprobe [Social Support Questionnaire (F-SozU): Norms from a representative sample]. Diagnostica, 45, 212-216. 
Fydrich, T., Sommer, G., Menzel, U., \& Höll, B. (1987). Fragebogen zur Sozialen Unterstützung (Kurzform; SOZU-K-22) [Social Support Questionnaire (short form)]. Zeitschrift für Klinische Psychologie, 16, 434-436.

Gidron, Y., Peri, T., Connolly, J. F., \& Shalev, A. Y. (1996). Written disclosure in posttraumatic stress disorder: Is it beneficial for the patients? Journal of Nervous and Mental Disorders, 184, 505-507.

Hardy, S. E., Concato, J., \& Gill, T. M. (2002). Stressful life events among community-living older persons. Journal of General Internal Medicine, 17, 841-847.

Holohan, C. K., \& Holohan, C. J. (1987). Self-efficacy, social support, and depression in aging: A longitudinal analysis. Journal of Gerontology, 42, 65-68.

Horowitz, M. J. (1997). Stress response syndromes (3rd ed.). Northvale, NJ: Aronson.

Jones, B., Müller, J., \& Maercker, A. (2006). Trauma and posttraumatic reactions in German development aid workers: Prevalences and relationship to social acknowledgement. International Journal of Social Psychiatry, 52, 91-100.

Jopp, D., \& Rott, C. (2006). Adaptation in very old age: exploring the role of resources, beliefs, and attitudes for centenarians' happiness. Psychology and Aging, 21, 266-280.

Kalbe, E., Kessler, J., Calabrese, P., Smith, R., Passmore, A. P., Brand, M., et al. (2004). DemTect: A new, sensitive cognitive screening test to support the diagnosis of mild cognitive impairment and early dementia. International Journal of Geriatric Psychiatry, 19, 136-143.

Krueger, N. F., Jr., \& Dickson, P. R. (1993). Self-efficacy and perceptions of opportunities and threats. Psychological Reports, 72, 1235-1240.

Kuhl, J. (2000). A functional-design approach to motivation and self-regulation. In M.

Boekaerts, P. R. Pintrich \& M. Zeidner (Eds.), Handbook of self-regulation (pp. 111169). San Diego, CA: Academic Press. 
Kuhl, J., \& Fuhrmann, A. (1998). Decomposing self-regulation and self-control: The Volitional Components Inventory. In J. Heckhausen \& C. S. Dweck (Eds.), Motivation and self-regulation across the life span (pp. 15-49). Cambridge, UK: Cambridge University Press.

Lepore, S. J., Silver, R., Wortman, C. B., \& Waymont, H. A. (1996). Social constraints, intrusive thoughts, and depressive symptoms among bereaved mothers. Journal of Personality and Social Psychology, 70, 271-282.

Luszczynska, A., Gutiérrez-Doña, B., \& Schwarzer, R. (2005). General self-efficacy in various domains of human functioning: Evidence from five countries. International Journal of Psychology, 40, 80-89.

Mackinnon, D. P., \& Dwyer, J. H. (1993). Estimating mediated effects in prevention studies. Evaluation Review, 17, 144-158.

Maercker, A., Einsle, F., \& Köllner, V. (2007). Adjustment disorders as stress response syndromes: A new diagnostic concept and its first exploration in a medical sample. Psychopathology, 40, 135-146.

Maercker, A., Forstmeier, S., Enzler, A., Krüsi, G., Helfenstein, E., Hörler, E., et al. (2008). Adjustment disorders, posttraumatic stress disorder, and depressive disorders in old age: Findings from a community survey. Comprehensive Psychiatry, 49, 113-120.

Maercker, A., \& Müller, J. (2004). Social acknowledgement as a victim or survivor: A scale to measure a recovery factor of PTSD. Journal of Traumatic Stress, 17, 345-351.

Maughan, B., \& Rutter, M. (1997). Retrospective reporting of childhood adversity: Issues in assessing long-term recall. Journal of Personality Disorders, 11, 19-33.

McCrae, R. R., \& Costa, P. T. (1988). Psychological resilience among widowed men and women: A 10-year follow-up of a national sample. Journal of Social Issues, 44, 129142. 
Mendes de Leon, C. F., Glass, T., Beckett, L. A., Seeman, T. E., Evans, D. A., \& Berkman, L. F. (1999). Social networks and disability transitions across eight intervals of yearly data in the New Haven EPESE. Journals of Gerontology Series B: Psychological Sciences and Social Sciences, 54, 162-172.

Müller, J., Beauducel, A., Raschka, J., \& Maercker, A. (2000). Kommunikationsverhalten nach politischer Haft in der DDR. Entwicklung eines Fragebogens zum Offenlegen der Traumaerfahrungen [Communication behavior after political imprisonment in the GDR: Development of a questionnaire on disclosure of trauma experiences]. Zeitschrift für Politische Psychologie, 4, 413-427.

Müller, J., Moergeli, H., \& Maercker, A. (2008). Disclosure and social acknowledgement as predictors of recovery from posttraumatic stress: A longitudinal study in crime victims. Canadian Journal of Psychiatry, 53, 160-168.

Pennebaker, J. W. (1993). Putting stress into words: Health, linguistic, and therapeutic implications. Behavioural Research and Therapy, 31, 539-548.

Rholes, W. S., Michas, L., \& Shroff, J. (1989). Action control as a vulnerability factor in dysphoria. Cognitive Therapy and Research, 13(3), 263-274.

Russell, D. W., \& Cutrona, C. E. (1991). Social support, stress, and depressive symptoms among the elderly: Test of a process model. Psychology and Aging, 6, 190-201.

Scholz, U., Gutierrez Dona, B., Sud, S., \& Schwarzer, R. (2002). Is general self-efficacy a universal construct? Psychometric findings from 25 countries. European Journal of Psychological Assessment, 18, 242-251.

Seagal, D. L., Bogaards, J. A., Becker, L. A., \& Chatman, C. (1999). Effects on emotional expression on adjustment to spousal loss among older adults. Journal of Mental Health and Aging, 5, 297-310. 
Smith, G. C., Kohn, S. J., Savage-Stevens, S. E., Finch, J. J., Ingate, R., \& Lim, Y. (2000). The effects of interpersonal and personal agency on perceived control and psychological well-being. Gerontologist, 40, 458-468.

Smith, K. P., \& Christakis, N. A. (2008). Social networks and health. Annual Review of Sociology, 34, 405-429.

Sobel, M. E. (1982). Asymptotic intervals for indirect effects in structural equation models. In S. Leinhart (Ed.), Sociological methodology (pp. 290-313). San Francisco, CA: Jossey-Bass.

Solomon, Z., Benbenishty, R., \& Mikulincer, M. (1991). The contribution of war time, prewar, and post-war factors to self-efficacy: a longitudinal study of combat stress reaction. Journal of Traumatic Stress, 4, 345-361.

Strain, J. J., Smith, G. C., Hammer, J. S., McKenzie, D. P., Blumenfield, M., Muskin, P., et al. (1998). Adjustment disorder: A multisite study of its utilization and interventions in the consultation-liaison psychiatry setting. General Hospital Psychiatry, 20, 139-149.

Stroebe, M., Stroebe, W., Schut, H., Zech, E., \& van den Bout, J. (2002). Does disclosure of emotions facilitate recovery from bereavement? Evidence from two prospective studies. Journal of Consulting and Clinical Psychology, 70, 169-178.

Tedeschi, R. G., \& Calhoun, L. G. (2004). Posttraumatic growth: Conceptual foundations and empirical evidence. Psychological Inquiry, 15, 1-18.

Uchino, B. N. (2009). What a lifespan approach might tell us about why distinct measures of social support have differential links to physical health. Journal of Social and Personal Relationships, 26, 53-62.

Ware, J. E., Kosinski, M., \& Keller, S. D. (1996). A 12-Item Short-Form Health Survey: Construction of scales and preliminary tests of reliability and validity. Medical Care, $34,220-233$. 
Table 1

Baseline Characteristics of the Sample by Sex $(N=121)$

\begin{tabular}{lllll}
\hline & & \multicolumn{3}{c}{ Sex } \\
\cline { 3 - 5 } Characteristic & Total & Female & Male & $t / \chi^{2}$ value \\
\hline Age (years), M (SD) & $75.2(8.0)$ & $75.1(7.9)$ & $75.4(8.4)$ & -0.21 \\
Age groups & & & & 0.80 \\
65-74, \% (n) & $56.2(68)$ & $58.8(50)$ & $50.0(18)$ & \\
75-84, \% (n) & $31.4(38)$ & $29.4(25)$ & $36.1(13)$ & \\
85+, \% (n) & $12.4(15)$ & $11.8(10)$ & $13.9(5)$ & \\
Sex (\% female) & $70.2(85)$ & & & \\
Education (years), M (SD) & $13.4(3.0)$ & $12.5(2.8)$ & $15.4(2.7)$ & $-5.43^{* * *}$ \\
Marital status & & & & $18.87^{* * *}$ \\
Married or living with a partner, \% (n) & $34.7(42)$ & $22.6(19)$ & $63.9(23)$ & \\
Not married (single, separated, widowed), \% (n) & $64.5(78)$ & $77.4(65)$ & $36.1(13)$ & \\
Living situation & & & & $18.57^{* * *}$ \\
$\quad$ Single, at home, \% (n) & $47.1(57)$ & $56.5(48)$ & $25.0(9)$ & \\
$\quad$ With partner, \% (n) & $31.4(38)$ & $20.0(17)$ & $58.3(21)$ & \\
$\quad$ With family member, \% (n) & $0.8(1)$ & $1.2(1)$ & $0(0)$ & \\
$\quad$ Old people's home, \% (n) & $19.0(23)$ & $20.0(17)$ & $16.7(6)$ & \\
$\quad$ With other persons, \% (n) & $1.7(2)$ & $2.4(2)$ & $0(0)$ & \\
Health, M (SD) & & & & \\
DemTect & $15.8(2.4)$ & $16.0(2.3)$ & $15.3(2.6)$ & 1.43 \\
Physical health (SF-12) & $41.2(4.7)$ & $40.8(4.7)$ & $42.1(4.6)$ & -1.36 \\
$\quad$ Mental health (SF-12) & $45.3(6.3)$ & $45.6(6.4)$ & $44.6(6.0)$ & 0.81 \\
\hline
\end{tabular}

Note. $* * p<.01 . * * * p<.001$. 
Table 2

Prevalence of and Index Stressors for Adjustment Disorder by Sex $(N=121)$

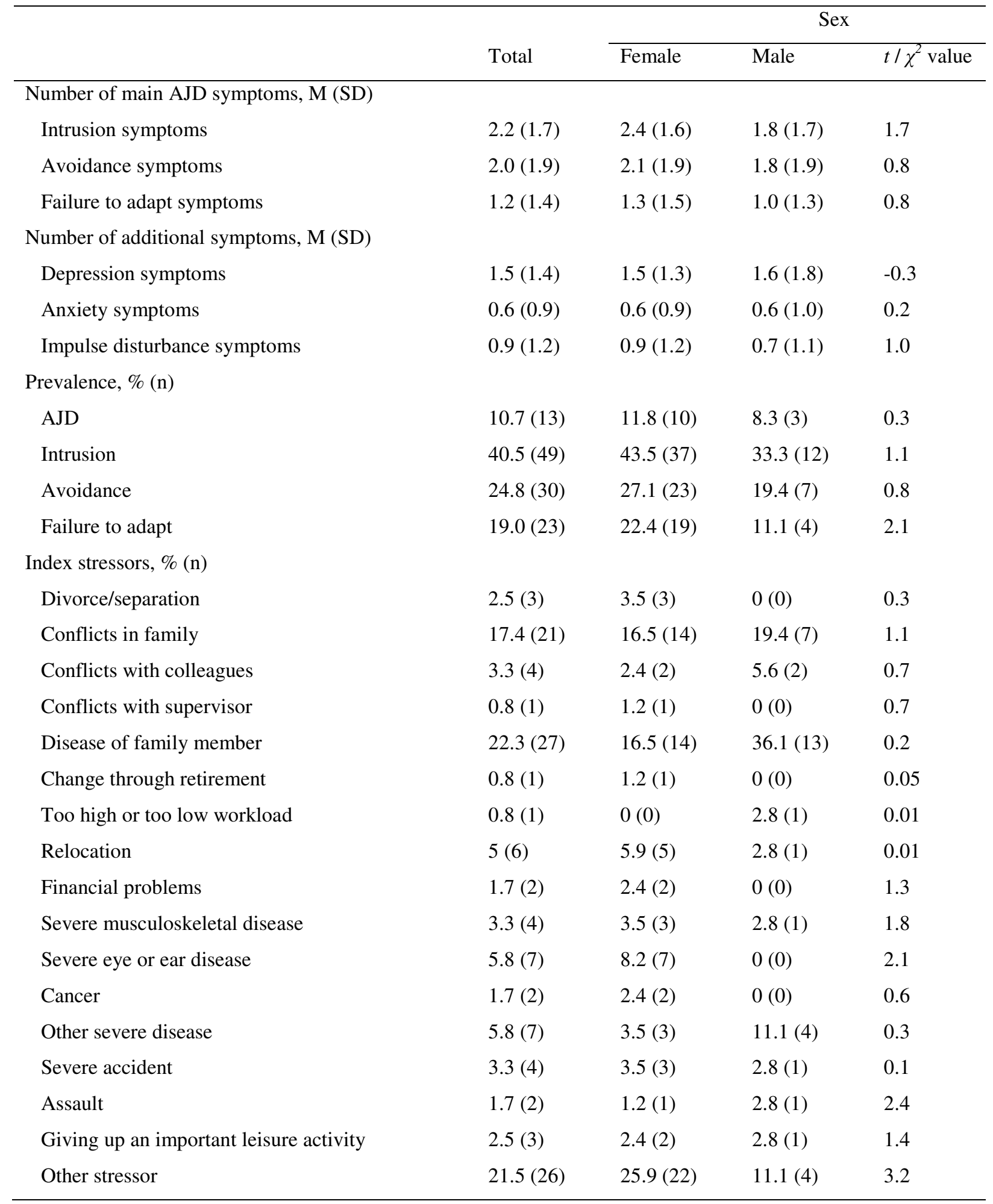


Table 3

Bivariate Correlations Among Study Variables $(N=121)$

\begin{tabular}{|c|c|c|c|c|c|c|c|c|c|c|c|c|c|c|c|}
\hline & 1 & 2 & 3 & 4 & 5 & 6 & 7 & 8 & 9 & 10 & 11 & 12 & 13 & 14 & 15 \\
\hline \multicolumn{16}{|l|}{ Sociodemographic characteristics } \\
\hline 1. Age group & 1.0 & & & & & & & & & & & & & & \\
\hline 2. Gender $(1=\mathrm{f} ; 2=\mathrm{m})$ & .07 & 1.0 & & & & & & & & & & & & & \\
\hline 3. Education (years) & .07 & $.45^{* *}$ & 1.0 & & & & & & & & & & & & \\
\hline 4. Marital status ( $0=$ not mar.; $1=$ mar. $)$ & $-.22 *$ & $.40 * *$ & $.18^{*}$ & 1.0 & & & & & & & & & & & \\
\hline \multicolumn{16}{|l|}{ Network characteristics } \\
\hline 5. Social support (FSozU) & -0.10 & -0.04 & -0.03 & 0.17 & 1.0 & & & & & & & & & & \\
\hline 6. Frequency of contact & 0.04 & -0.06 & -0.02 & $.25^{* *}$ & 0.17 & 1.0 & & & & & & & & & \\
\hline \multicolumn{16}{|l|}{ Disclosure } \\
\hline 7. Reluctance to talk & 0.02 & $-.20^{*}$ & -0.17 & -0.09 & $-.22 *$ & -0.04 & 1.0 & & & & & & & & \\
\hline 8. Urge to talk & -0.16 & 0.09 & 0.11 & $.20^{*}$ & 0.17 & 0.04 & -0.11 & 1.0 & & & & & & & \\
\hline 9. Emotional reaction & $-.27 * *$ & -0.12 & -0.09 & -0.06 & 0.05 & 0.01 & $.43 * *$ & 0.13 & 1.0 & & & & & & \\
\hline \multicolumn{16}{|l|}{ Social acknowledgment } \\
\hline 10. Recgnition as a victim & 0.08 & 0.02 & 0.16 & 0.07 & $.51 * *$ & 0.13 & -0.14 & 0.10 & 0.12 & 1.0 & & & & & \\
\hline 11. General disapproval & 0.12 & -0.17 & -0.06 & $-.23 *$ & $-.36 * *$ & -0.10 & $.52 * *$ & 0.11 & $.32 * *$ & -0.15 & 1.0 & & & & \\
\hline 12. Family disapproval & -0.06 & -0.05 & -0.05 & -0.11 & $-.41 * *$ & -0.09 & $.36^{* *}$ & -0.07 & $.18^{*}$ & $-.42 * *$ & $.47 * *$ & 1.0 & & & \\
\hline 13. Total score & 0.01 & 0.11 & 0.11 & 0.18 & $.58 * *$ & 0.14 & $-.44 * *$ & 0.00 & -0.16 & $.73 * *$ & $-.71 * *$ & $-.81 * *$ & 1.0 & & \\
\hline \multicolumn{16}{|l|}{ Motivational abilities } \\
\hline 14. Motivational variables & -0.06 & 0.08 & 0.10 & 0.07 & $.26^{* *}$ & 0.03 & $-.18^{*}$ & -0.03 & -0.05 & $.30 * *$ & -0.14 & -0.06 & $.28^{* *}$ & 1.0 & \\
\hline 15. General self-efficacy & -0.15 & 0.05 & 0.05 & 0.14 & $.28 * *$ & 0.12 & $-.26^{* *}$ & 0.07 & -0.05 & $.25^{* *}$ & -0.17 & $-.20 *$ & $.31 * *$ & $.51 * *$ & 1.0 \\
\hline
\end{tabular}


16. No. of main symptoms $-.20 * \quad-0.12$ 0.12 $-0.07$ $-0.02$ 0.04 $.37 * * \quad 0.12$ $.60 * * \quad 0.05$ $.41 * * \quad .21 *$ $-.27 * *$ $-.32 * *$ Note. The values represent Pearson correlations (between two continuous variables), point-biserial correlations (between a continuous and a dichotomous variable), or phi coefficients (between two dichotomous variables). 
Table 4

Summary of Multiple Hierarchical Regression Analyses Predicting the Number of Main Symptoms of Adjustment Disorder $(N=121)$

\begin{tabular}{|c|c|c|c|c|c|}
\hline & $B$ & $S E$ & $\beta$ & $\Delta R^{2}$ & $\Delta F$ \\
\hline Step 1: Sociodemographic characteristics & & & & .11 & $3.71 * *$ \\
\hline \multicolumn{6}{|l|}{ and health } \\
\hline Age group & -1.36 & .50 & $-.23 * *$ & & \\
\hline Gender $(1=\mathrm{f} ; 2=\mathrm{m})$ & -1.3 & .89 & -.11 & & \\
\hline Education (in years) & .31 & .13 & $.22 * *$ & & \\
\hline Marital status ( $0=$ not mar.; $1=$ mar. $)$ & -.25 & .82 & -.03 & & \\
\hline Mental health & -.09 & .06 & -.14 & & \\
\hline Step 2: Interpersonal resources & & & & .08 & $6.37 * *$ \\
\hline Disclosure: Reluctance to talk & .28 & .09 & $.31 * * *$ & & \\
\hline Social acknowledgment: Total score & -.004 & .05 & -.01 & & \\
\hline Step 3: Motivational variables & & & & .07 & $5.33 * *$ \\
\hline Motivation regulation & -.36 & .13 & $-.25 * *$ & & \\
\hline General self-efficacy & -.04 & .09 & -.04 & & \\
\hline
\end{tabular}

Note. $\Delta R^{2}$ reported for cases in which the respective block was included in the final step of the analysis.

$R^{2}=0.33, F(9,110)=5.92, p<.001$.

$* p<.05 . * * p<.01 . * * * p<.001$. 
Table 5

Summary of Regression Analyses for Motivational Variables Mediating the Relationship Between Interpersonal Resources and Number of Main Symptoms of Adjustment Disorder ( $N$ $=121)$

\begin{tabular}{|c|c|c|c|c|c|c|c|}
\hline & $B$ & $S E$ & $\beta$ & $\Delta R^{2}$ & $\Delta F$ & $R^{2}$ & $F$ \\
\hline \multicolumn{8}{|l|}{ Step 1} \\
\hline M1 and M2 & & & & & & .26 & $6.75^{* * *}$ \\
\hline Disclosure: Reluctance to talk & .31 & .08 & $.34 * * *$ & & & & \\
\hline M3 and M4 & & & & & & .19 & $4.35 * *$ \\
\hline Social acknowledgment: Total score & -.11 & .04 & $-.21 *$ & & & & \\
\hline \multicolumn{8}{|l|}{ Step 2} \\
\hline M1 & & & & & & .33 & $7.65^{* * *}$ \\
\hline Disclosure: Reluctance to talk & .28 & .08 & $.30 * * *$ & & & & \\
\hline Motivation regulation & -.38 & .11 & $-.26 * * *$ & .07 & $10.97^{* *}$ & & \\
\hline M2 & & & & & & .28 & $6.45 * * *$ \\
\hline Disclosure: Reluctance to talk & .27 & .08 & $.30^{* *}$ & & & & \\
\hline General self-efficacy & -.15 & .08 & -.16 & .02 & 3.7 & & \\
\hline M3 & & & & & & .26 & $5.48 * * *$ \\
\hline Social acknowledgment: Total score & -.07 & .04 & -.14 & & & & \\
\hline Motivation regulation & -.39 & .12 & $-.27 * *$ & .07 & $10.16^{* *}$ & & \\
\hline M4 & & & & & & .22 & $4.54 * * *$ \\
\hline Social acknowledgment: Total score & -.07 & .05 & -.14 & & & & \\
\hline General self-efficacy & -.18 & .08 & $-.20 *$ & .03 & $4.8^{*}$ & & \\
\hline
\end{tabular}

Note. Age, gender, education, marital status, and mental health were controlled for in every analysis. Four separate hierarchical regression analyses are reported in this table. Model 1: motivation regulation as a mediator between reluctance to talk and AJD symptoms; model 2: general self-efficacy as a mediator between reluctance to talk and AJD symptoms; model 3: motivation regulation as a mediator between social acknowledgment and AJD symptoms; model 4: general self-efficacy as a mediator between social acknowledgment and AJD symptoms.

$* p<.05 . * * p<.01 . * * * p<.001$. 
Table 6

Summary of Regression Analyses for Interpersonal Resources Mediating the Relationship Between Motivational Variables and Number of Main Symptoms of Adjustment Disorder (N $=121)$

\begin{tabular}{|c|c|c|c|c|c|c|c|}
\hline & $B$ & $S E$ & $B$ & $\Delta R^{2}$ & $\Delta F$ & $\overline{R^{2}}$ & $F$ \\
\hline \multicolumn{8}{|l|}{ Step 1} \\
\hline M5 and M6 & & & & & & .25 & $6.27 * * *$ \\
\hline Motivation regulation & -.43 & .12 & $-.30^{* * *}$ & & & & \\
\hline M7 and M8 & & & & & & .21 & $5.20 * * *$ \\
\hline General self-efficacy & -.22 & .08 & $-.24 * *$ & & & & \\
\hline \multicolumn{8}{|l|}{ Step 2} \\
\hline M5 & & & & & & .33 & $7.85^{* * *}$ \\
\hline Motivation regulation & -.38 & .11 & $-.26 * *$ & & & & \\
\hline Disclosure: Reluctance to talk & .28 & .08 & $.30 * * *$ & .08 & $13.31 * * *$ & & \\
\hline M6 & & & & & & .26 & $5.48 * * *$ \\
\hline Motivation regulation & -.39 & .12 & $-.27 * *$ & & & & \\
\hline Social acknowledgment: Total score & -.07 & .04 & -.14 & .02 & 2.38 & & \\
\hline M7 & & & & & & .28 & $6.45 * * *$ \\
\hline General self-efficacy & -.15 & .08 & -.16 & & & & \\
\hline Disclosure: Reluctance to talk & .27 & .08 & $.30 * *$ & .07 & $11.18^{* *}$ & & \\
\hline M8 & & & & & & .22 & $4.54 * * *$ \\
\hline General self-efficacy & -.18 & .08 & $-.20^{*}$ & & & & \\
\hline Social acknowledgment: Total score & -.07 & .05 & -.14 & .02 & 2.45 & & \\
\hline
\end{tabular}

Note. Age, gender, education, marital status, and mental health were controlled for in every analysis. Four separate hierarchical regression analyses are reported in this table. Model 5: reluctance to talk as a mediator between motivation regulation and AJD symptoms; model 6: social acknowledgment as a mediator between motivation regulation and AJD symptoms; model 7: reluctance to talk as a mediator between general self-efficacy and AJD symptoms; model 8: social acknowledgment as a mediator between general self-efficacy and AJD symptoms.

$* p<.05 . * * p<.01 . * * * p<.001$. 


\section{Figure Captions}

Figure 1. Mediation regression analysis for number of main symptoms of adjustment disorder, including beta-weights, $F$ values, and $\mathrm{R}^{2} \mathrm{~s}$ for the model before (reduced model) and after (full model) inclusion of the mediator (upper part: general self-efficacy; lower part:

reluctance to talk). The initial path between the predictor (upper part: social acknowledgment; lower part: general self-efficacy) and adjustment disorder is indicated by the beta-weight above the line connecting these variables; the beta-weight after inclusion of the mediator is indicated by the value below this line. 

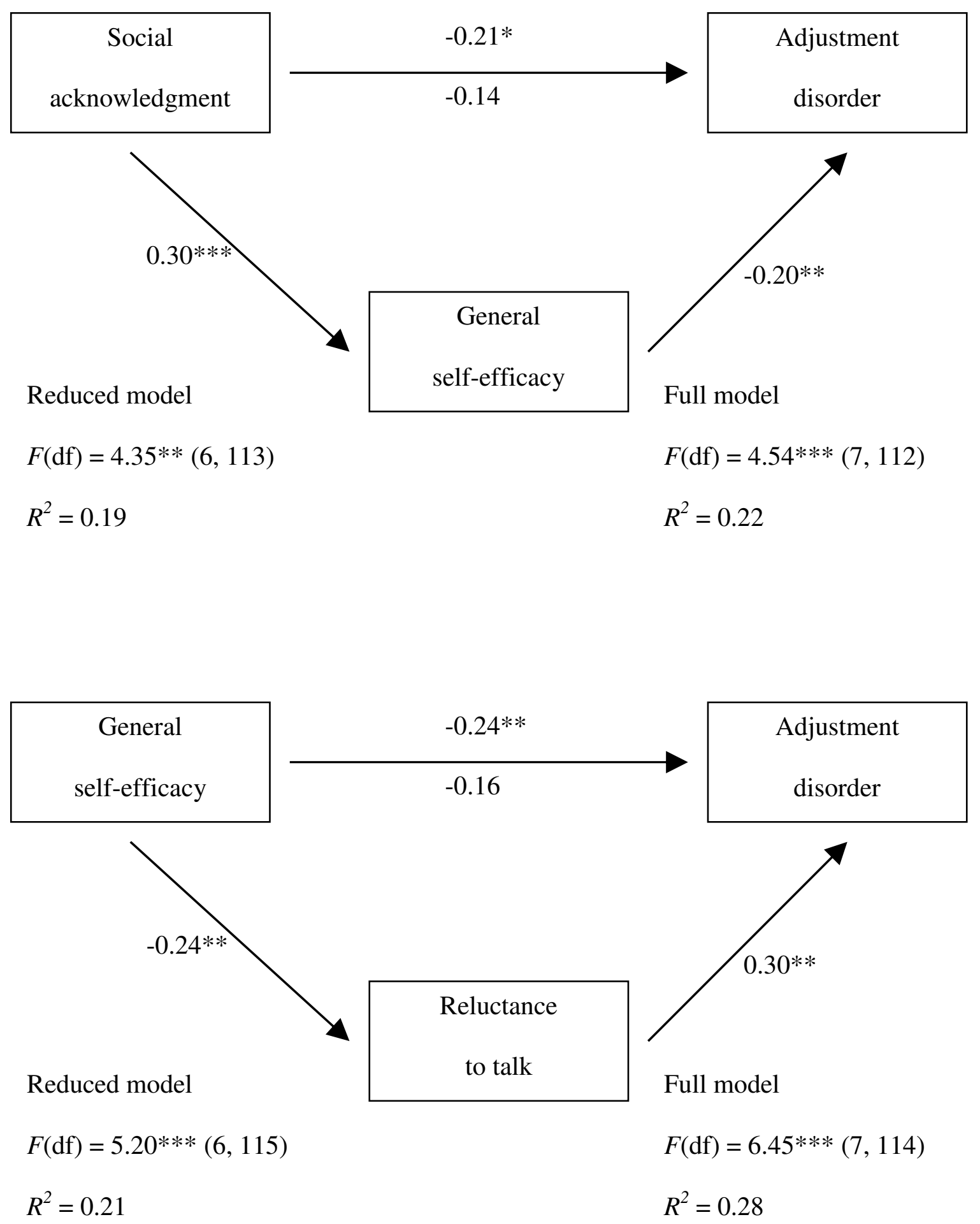

Note. $* p<.05 . * * p<.01 . * * * p<.001$. 